\title{
Detecting Autism Spectrum Disorder from Early Intervention Charts: Methodology and Preliminary Findings
}

\author{
Patricia O. Towle $\cdot$ Paul F. Visintainer · \\ Colleen O'Sullivan · N. Elizabeth Bryant • \\ Suzanne Busby
}

Published online: 2 December 2008

(C) Springer Science+Business Media, LLC 2008

\section{Erratum to: J Autism Dev Disord \\ DOI 10.1007/s10803-008-0643-x}

The correct name of the affiliation for Elizabeth Bryant is Partners for Inclusive Communities.

The online version of the original article can be found under doi:10.1007/s10803-008-0643-x.

\section{P. O. Towle}

School of Public Health, New York Medical College, Valhalla, NY, USA

P. O. Towle $(\varangle) \cdot$ C. O’Sullivan · N. E. Bryant · S. Busby Westchester Institute for Human Development, Cedarwood Hall, Valhalla, NY 10595, USA

e-mail: ptowle@wihd.org

\section{P. F. Visintainer}

Department of Biostatistics, School of Public Health, New York Medical College, Valhalla, NY 10595, USA

\section{N. E. Bryant}

Partners for Inclusive Communities, University of Arkansas for Medical Sciences, 2001 Pershing Cir., Ste 300, North Little Rock, AR 72114, USA

Present Address:

C. O'Sullivan

Chappaqua School District, Chappaqua, NY, USA

Present Address:

S. Busby

Department of Psychology, State University of New York

at New Paltz, New Paltz, NY, USA 